32

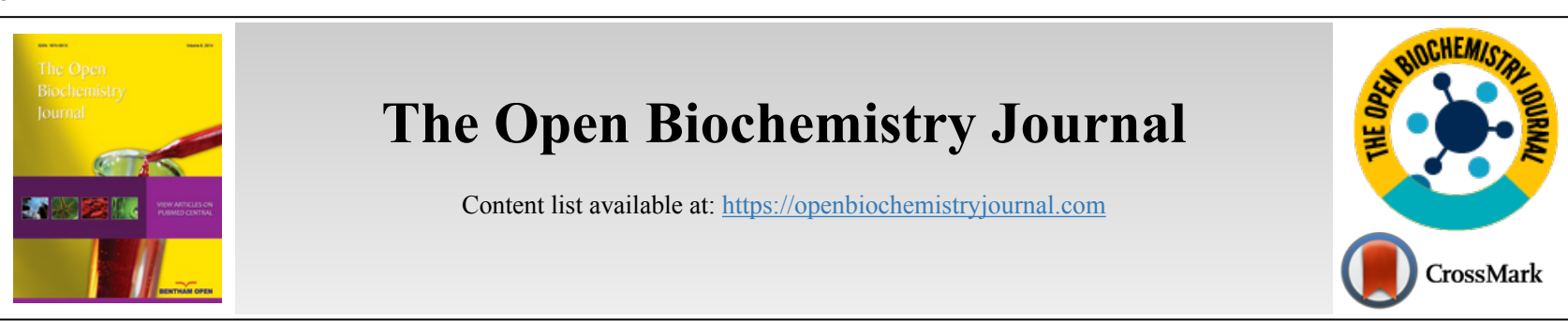

RESEARCH ARTICLE

\title{
Investigation of Blood and Urine Malondialdehyde Levels in Mice Exposed to Silica Dust
}

\author{
Abdollah Gholami ${ }^{1}$, Farideh Golbabaei $i^{2, *}$, Gholamheidar Teimori ${ }^{3,4}$, Mojtaba Kianmehr ${ }^{5}$ and Mehdi Yaseri ${ }^{6}$ \\ ${ }^{I}$ Department of Occupational Health Engineering, School of Public Health, Birjand University of Medical Sciences, Birjand, Iran \\ ${ }^{2}$ Department of Occupational Health Engineering, School of Public Health, Tehran University of Medical Sciences, Tehran, Iran \\ ${ }^{3}$ Department of Environmental Health, School of Health, Torbat Heydariyeh University of Medical Sciences, Torbat Heydariyeh, Iran \\ ${ }^{4}$ Health Sciences Research Center, School of Health, Torbat Heydariyeh University of Medical Sciences, Torbat Heydariyeh, Iran \\ ${ }^{5}$ Department of Basic Sciences, Faculty of Medicine, Gonabad University of Medical Sciences, Gonabad, Iran \\ ${ }^{6}$ Department of Biostatistics, School of Public Health, Tehran University of Medical Sciences, Tehran, Iran
}

\begin{abstract}
:
Background and Objectives:

Occupational exposure to silica dust can lead to biochemical damage. Malondialdehyde (MDA) can be considered as a primary marker for measuring the level of oxidative stress in a living organism. This study was conducted in order to evaluate the level of MDA in blood and urine of mice exposed to silica dust.

\section{Material and Methods:}

In this experimental study, 72 mice (BALB/c) were randomly allocated to five exposed groups and 1 control group. Exposure of mice to pure $99 \%$ silica dust was done in closed containers. Blood sampling was performed from the heart of mice and urine sampling fulfilled by insertion into a metabolic cage. The RAO et al. method was used to measure MDA.

Results:

The highest level of plasma MDA in group 1 in the $4^{\text {th }}$ month was $8.4 \pm 0.41 \mathrm{nmol} / 1$ and the lowest level of MDA was $1.3 \pm 0.2 \mathrm{nmol} / 1$ in the third sampling in the control group, also the highest amount of urine MDA in the first and second groups and 4 months after exposure was $1.16 \pm 0.51$ $\mathrm{nmol} / \mathrm{l}$, and the lowest in the control group and in the third sampling was $0.48 \pm 0.06 \mathrm{nmol} / \mathrm{l}$. A significant difference was found between the levels of MDA in all exposed groups at different times except for the $5^{\text {th }}$ group with the lowest concentration $(P<0.05)$.

Conclusion:

MDA in blood and urine could be proposed as a good biomarker for the evaluation of biochemical damages caused by silica dust. Measuring MDA is also a simple and inexpensive method that does not require complex equipment and can be used as an early detection test for biochemical damages caused by silica.
\end{abstract}

Keywords: Biomarker, Crystalline silica, Dust, Mouse, Malondialdehyde, Biochemical damages.

\begin{tabular}{|l|l|l|r|}
\hline Article History & Received: December 05, 2018 & Revised: March 05, 2019 & Accepted: March 10, 2019
\end{tabular}

\section{INTRODUCTION}

Silica is the most common mineral on earth and is one of the materials used in various mineral industries such as casting, glass processing, tile and ceramic factories, cleaners, supply of various chemicals and glazes, as well as in open and underground mines [1]. In such work environments, contact with air-

* Address correspondence to this author at the Department of Occupational Health,School of Public Health, Tehran University of Medical Sciences, Iran; Tel: +9821-88951390; E-mail: fgolbabaei@tums.ac.ir borne particles and dust is common and can cause many problems with regard to occupational and workers' health. Continuous inhalation of dust containing crystalline silica causes one of the most important pulmonary diseases called silicosis. In addition to silicosis, lung cancer, renal diseases and DNA damage (deoxyribonucleic acid), biochemical complications, and other complications have also been reported [2 - 5].

One of the damages caused by silica is biochemical damage that is studied by measuring biochemical indicators in the blood or urine. In previous field studies conducted on wor- 
kers exposed to crystalline silica, a significant difference was observed between the levels of Malondialdehyde (MDA) in workers exposed to silica compared to the control group [6 - 8].

No valid biomarker has been recommended for early diagnosis and measurement of the progression of silicosis so far $[5,9]$. Aldehydes are produced from the oxidation of phospholipids in a cell membrane [10], and MDA is a secondary compound formed by the peroxidation of unsaturated fatty acids in the body that can be used as a marker to measure the level of oxidative stress in a living organism. On the other hand, since MDA is an active and highly reactive compound, with other attacking molecules,maintaining covalent bonding affects the function of the molecules and, finally, the cell's function [11 - 13].

The body cells are always exposed to various oxidizing substances. The Reactive Oxygen Species (ROS), which contain highly active oxygen molecules, are commonly used oxidizing compounds. These compounds attack different molecules, oxidize them, and produce secondary oxidation products. Lipids are the most important category of biomolecules that target reactive oxygen species. In fact, oxidative degradation of lipids by reactive oxygen species is called lipid peroxidation. Lipid peroxidation is usually performed on unsaturated fatty acids, and the final product is active aldehydes such as MDA [14 - 17]. Increasing levels of MDA and reducing the antioxidant defense system in the body can lead to cellular degradation [18]. The study of Khosrowbeigi et al. showed that lipid peroxidation of the membrane of the sperm increased the level of MDA and may be an important factor in reducing sperm motility [19]. According to previous studies, exposure to harmful noise in the workplace and/or smoking causes increased levels of MDA in individuals, which can increase the level of MDA in patients exposed to silica simultaneously $[20,21]$. In the study by Zare Sakhvidi et al., MDA level in exhale of workers exposed to silica dust was measured that did not differ significantly, but a positive and significant relationship was found between the intensity of exposure to dust and MDA in exhale of workers [22].

Determination of the amount of silica dust in various types of operations and mineral processes, and, also the influence of silica dust on genetic and biochemical damages is necessary. In this study, an animal study was used to remove the inevitable confounding factors present in the real space of the mines, and the studied mice were only exposed to silica dust. The results of this animal study could be used to validate the human study. Therefore, this study was conducted aimed to determine the level of MDA in blood and urine of the mice exposed to silica dust.

\section{MATERIALS AND METHODS}

In this experimental study, 72 mice (BALB/c) from the experimental center of Birjand University of Medical Sciences were evaluated to determine the effect of silica dust on the level of MDA in the mice blood and urine. The animals were kept in special animal shelves under standard dark conditions and free access to sufficient water and food at a temperature of
$23 \pm 2^{\circ} \mathrm{C}$. All experiments were performed in accordance with the international guidelines for working with experimental animals. The study was approved by the Ethics Committee of Tehran University of Medical Sciences and attempted to minimize the stress levels of the studied mice.

In this study, the mice were divided into 5 exposure groups and one control group. The mice in exposure groups were exposed to silica dust concentrations and the mice in the control group were not exposed to any chemical or other agents. The mice maintenance environment and diet were the same in all groups. The mice were exposed to silica dust in closed containers. The mice were exposed to silica for 8 hours a day, 6 days a week and 1, 2, 3 and 4 months, respectively. The silica used in this study was made of pure $99 \%$ silica, processed in Iran's mines, which is mostly used as casting sand and raw materials in tile and ceramic industries and glass factories.

\subsection{Exposure to Silica Dust}

The mice exposure containers with silica dust were $25 \times 15 \times 30 \mathrm{~cm}^{3}$ seamless plastic containers fitted with 3 control valves, through a valve dust was inserted into the container from a uniform one, by another valve, the clean air was fed into the container and another valve was used for sampling and measuring dust inside the container by TSI device. The dust was created by a blower pump inside a container containing silica powder and introduced into a large glass container for first uniformity of dust, and then was guided through the hoses of the connector into the containers. Control valves were used to adjust dust concentration inside the containers. With measuring the amount of silica dust, the valve of the dust concentration in each container was controlled. Finally, the mean concentration during the exposure period was calculated. Fig. (1) shows a schematic representation of the system of the mice exposure to silica dust.

\subsection{Measurement of MDA}

In order to determine the level of MDA in mice blood and urine, blood sampling from the mice heart was performed and urine sampling fulfilled by insertion in a metabolic cage. The RAO et al. method was used to measure MDA. In this method, the amount of MDA is measured by Thiobarbituric method. For test, $100 \mu \mathrm{l}$ of the serum sample was added to $900 \mu \mathrm{l}$ of distilled water, then $500 \mu 1$ of TBA agent was added to the diluted sample, placed at $100{ }^{\circ} \mathrm{C}$ for $1 \mathrm{~h}$, after cooling the samples were centrifuged for 10 minutes at $4000 \mathrm{rpm}$ and finally the supernatant is separated and optical absorbance of the samples is read by using a spectrophotometer at $534 \mathrm{~nm}$ wavelength. Using the silence factor $(105 \times 1.56)$, the concentration of MDA is calculated and the results are reported in micromoles per liter. Each experiment was repeated on each sample 3 times, and then the results were recorded as the mean.

\subsection{Statistical Analysis}

In order to study and analyze the data, software SPSS 21, one way ANOVA and Tukey post hoc tests were used. The significance level was less than 0.05 . 


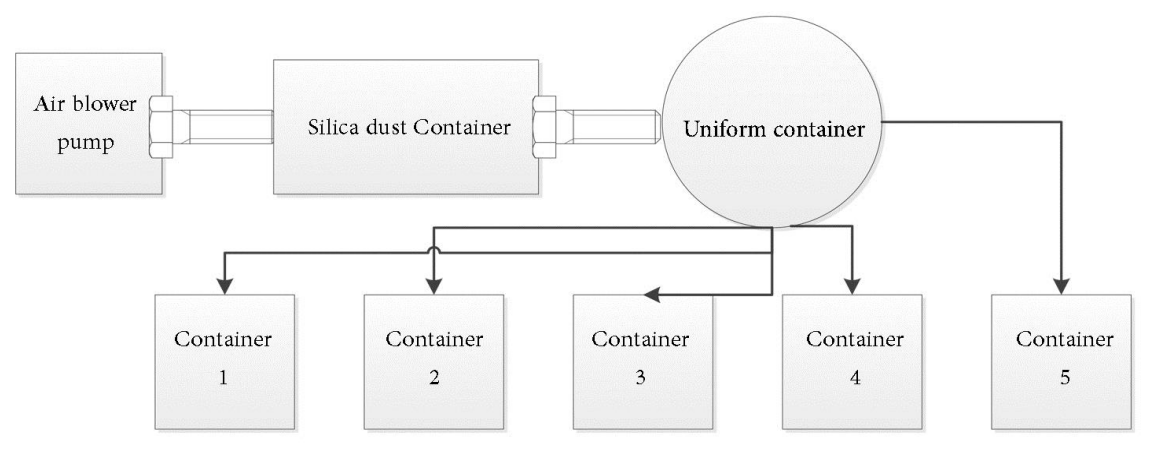

Fig (1). Schematic representation of the system of the mice exposure to silica dust.

\section{RESULTS}

The mean concentration and distribution of total dust size of exposure to silica in various containers are presented in Table 1. The highest concentration of exposure to dust in different groups was related to the container No.1. (Table 2) illustrates the mean of MDA (nmol/1) in blood plasma of the mice exposed to dust. The highest level of MDA in group 1 in the 4th month was $8.4 \pm 0.41 \mathrm{nmol} / 1$ and the lowest level of MDA in the third sampling in the control group was $1.3 \pm 0.2$ $\mathrm{nmol} / 1$. Using ANOVA test, a significant difference was observed between the levels of blood plasma MDA in all groups exposed at different times except group 5 with the lowest concentration $(P<0.05)$.

The mean urine MDA (nmol/l) of mice exposed to dust is shown in Table 3. The highest level of urine MDA in groups 1 and 2 and the fourth month after exposure was $1.16 \pm 0.51$ $\mathrm{nmol} / 1$ and the lowest level of MDA in the control group and in the third sampling was $0.48 \pm 0.06 \mathrm{nmol} / \mathrm{l}$. The results of ANOVA statistical test showed a significant difference between the levels of urine MDA in all the different groups exposed at different times except for the group 5 with the lowest concentration $(P<0.05)$.

Table 1. The mean concentration and distribution of silica dust in different containers of exposure.

\begin{tabular}{|c|c|c|c|c|c|}
\hline \multicolumn{7}{|c|}{ Dust concentration $\left.\mathbf{( m g} / \mathbf{m}^{\mathbf{3}}\right)$} & $\mathbf{P M}_{\mathbf{1 0}}$ & Total $^{\mathbf{2}}$ \\
\hline Container & $\mathbf{P M}_{\mathbf{1}}$ & $\mathbf{P M}_{\mathbf{2 . 5}}$ & $\mathbf{P M}_{\mathbf{5}}$ & 15.5 & 17 \\
\hline 1 & 6.8 & 7.8 & 11.7 & 10.5 & 12 \\
\hline 2 & 4.9 & 5.56 & 8.32 & 6.59 & 8 \\
\hline 3 & 3.1 & 3.7 & 5.74 & 2.7 & 3 \\
\hline 4 & 1.42 & 1.9 & 2.013 & 1.23 & 1.3 \\
\hline 5 & 0.82 & 1.01 & 1.22 & 0 & 0 \\
\hline $6($ Control) & 0 & 0 & 0 & & \\
\hline
\end{tabular}

Table 2. The mean malondialdehyde (n mol/l) of blood plasma of mice exposed to dust.

\begin{tabular}{|c|c|c|c|c|c|c|}
\hline Exposure time & Group 1 & Group 2 & Group 3 & Group 4 & Group 5 & Control \\
\hline 1 month & $3.8 \pm 0.52$ & $5.2 \pm 2.5$ & $4.06 \pm 2.7$ & $3.2 \pm 1$ & $1.53 \pm 0.66$ & $4.3 \pm 2.8$ \\
\hline 2 month & $5.1 \pm 0.152$ & $4.7 \pm 0.95$ & $3.8 \pm 0.66$ & $4.1 \pm 0.57$ & $3.23 \pm 0.57$ & $1.5 \pm 0.47$ \\
\hline 3 month & $7.3 \pm 0.57$ & $6.1 \pm 0.78$ & $5.5 \pm 1.09$ & $5.9 \pm 0.85$ & $4.3 \pm 1.1$ & $1.3 \pm 0.2$ \\
\hline 4 month & $8.4 \pm 0.41$ & $6.8 \pm 0.57$ & $6.6 \pm 0.43$ & $6.6 \pm 0.38$ & $6.1 \pm 0.57$ & $1.8 \pm 0.58$ \\
\hline$p$-value & 0.001 & 0.001 & 0.003 & 0.001 & 0.26 & - \\
\hline
\end{tabular}

Table 3. The mean malondialdehyde ( $\mathrm{n} \mathrm{mol} / \mathrm{l})$ of urine of mice exposed to dust.

\begin{tabular}{|c|c|c|c|c|c|c|}
\hline Exposure time & Group 1 & Group 2 & Group 3 & Group 4 & Group 5 & Control \\
\hline 1 month & $0.97 \pm 0.0057$ & $0.15 \pm 0.159$ & $0.84 \pm 0.44$ & $0.803 \pm 0.37$ & $0.1 \pm 0.054$ & $0.55 \pm 0.1$ \\
\hline 2 month & $1.09 \pm 0.11$ & $0.87 \pm 0.011$ & $0.98 \pm 0.22$ & $0.88 \pm 0.1$ & $0.67 \pm 0.11$ & $0.55 \pm 0.1$ \\
\hline 3 month & $1.2 \pm 0.15$ & $1.02 \pm 0.06$ & $1.02 \pm 0.21$ & $0.712 \pm 0.56$ & $0.803 \pm 0.21$ & $0.48 \pm 0.6$ \\
\hline 4 month & $1.16 \pm 0.51$ & $1.16 \pm 0.57$ & $1.16 \pm 0.72$ & $0.02 \pm 0.06$ & $0.73 \pm 0.21$ & $0.51 \pm 0.12$ \\
\hline$p$-value & 0.0001 & 0.007 & 0.001 & 0.023 & 0.704 & - \\
\hline
\end{tabular}




\section{DISCUSSION}

In order to evaluate oxidative stress, measurement of MDA produced in the peroxidation lipid process is used [23]. The amount of MDA produced is proportional to the failure and separation of unsaturated fatty acids. Therefore, the measurement of MDA in various biological samples is a good index for lipid peroxidation and can be used as a marker for measuring oxidative stress levels in a living organism [24].

According to conducted studies, one of the biochemical studies of exposure to silica has been suggested through a review of blood and urine MDA [23, 25]. Hence, in the present animal study, the level of MDA in blood and urine of the mice exposed to silica dust was studied. The study results showed that with increasing the level of silica dust and exposure time, the level of MDA in blood and urine in mice increased, so that in groups 5 and 4 most exposed for a long time the highest level of MDA was found in their blood and urine, and in all groups, the level of MDA in blood and urine was significantly different from that of the control group. In a study by Azari et al., which was conducted on workers exposed to silica in sandblasting, the concentration of urine MDA and neoprene in workers exposed to silica was higher than that of the control group [8].

In a study by Kamal et al. on workers exposed to silica in Egypt, serum MDA concentration was higher in workers exposed to silica, which is consistent with the results of the present study [7]. In a study by Jafari et al. on workers exposed to silica in sandblasting, the level of MDA and neoprene urine in workers exposed to silica was higher than that of the control group [26]. In a study by Orman et al. on cement workers in Turkey, MDA plasma was significantly increased in workers exposed to silica compared to the control group [6] which is consistent with the results of the present study. The difference in MDA levels in the experimental and control groups indicates lipid oxidation in the mice exposed to silica dust, indicating that MDA can be used as a biomarker for workers exposed to silica dust.

A significant difference was observed between the levels of MDA in urine and blood in all groups at different times, except for the 5th group with the lowest concentration, indicating that the amount of silica dust and exposure time can cause increasing MDA level in the mice.

Given that in several human studies a significant difference was observed between the levels of MDA in groups exposed to silica dust and the control group, it seems necessary to conduct a study with more samples in a longer period of time.

\section{CONCLUSION}

The study results showed that MDA in blood and urine could be an appropriate biomarker for the evaluation of silica dust damages. Measuring MDA is a simple and inexpensive method that does not require complex equipment and can be used as an early detection test for biochemical damages caused by silica.

\section{ETHICS APPROVAL AND CONSENT TO PARTI- CIPATE}

This study was approved by Birjand University of Medical Sciences, Birjand, Iran.

\section{HUMAN AND ANIMAL RIGHTS}

No humans were involved in this study. All procedures were performed in accordance with the standards of The US Public Health Service's "Policy on Humane Care and Use of Laboratory Animals," and "Guide for the Care and Use of Laboratory Animals."

\section{CONSENT FOR PUBLICATION}

Not applicable.

\section{FUNDING}

None.

\section{CONFLICT OF INTEREST}

The authors declare no conflict of interest, financial or otherwise.

\section{ACKNOWLEDGMENTS}

Declared none.

\section{REFERENCES}

[1] Altindag, Z.Z.; Baydar, T.; Isimer, A.; Sahin, G. Neopterin as a new biomarker for the evaluation of occupational exposure to silica. Int. Arch. Occup. Environ. Health, 2003, 76(4), 318-322. [PMID: 12768284]

[2] Davis, G.S. Pathogenesis of silicosis: current concepts and hypotheses. Hai, 1986, 164(3), 139-154.

[http://dx.doi.org/10.1007/BF02713638] [PMID: 3088337]

[3] Hnizdo, E.; Murray, J. Risk of pulmonary tuberculosis relative to silicosis and exposure to silica dust in South African gold miners. Occup. Environ. Med., 1998, 55(7), 496-502. [http://dx.doi.org/10.1136/oem.55.7.496] [PMID: 9816385]

[4] Hnizdo, E.; Vallyathan, V. Chronic obstructive pulmonary disease due to occupational exposure to silica dust: a review of epidemiological and pathological evidence. Occup. Environ. Med., 2003, 60(4), 237-243.

[http://dx.doi.org/10.1136/oem.60.4.237] [PMID: 12660371]

[5] Huaux, F. New developments in the understanding of immunology in silicosis. Curr. Opin. Allergy Clin. Immunol., 2007, 7(2), 168-173. [http://dx.doi.org/10.1097/ACI.0b013e32802bf8a5] [PMID: 17351 471]

[6] Orman, A.; Kahraman, A.; Çakar, H.; Ellidokuz, H.; Serteser, M. Plasma malondialdehyde and erythrocyte glutathione levels in workers with cement dust-exposure . Toxicology, 2005, 207(1), 15-20. [http://dx.doi.org/10.1016/j.tox.2004.07.021] [PMID: 15590118]

[7] Kamal, A-A.M.; Gomaa, A.; el Khafif, M.; Hammad, A.S. Plasma lipid peroxides among workers exposed to silica or asbestos dusts. Environ. Res., 1989, 49(2), 173-180.

[http://dx.doi.org/10.1016/S0013-9351(89)80062-3] [PMID: 2546756]

[8] Azari, M.R.; Ramazani, B.; Mosavian, M.A.; Movahadi, M.; Salehpour, S. Serum malondialdehyde and urinary neopterin levels in glass sandblasters exposed to crystalline silica aerosols. Int. J. Occup. Hyg., 2011, 3(1), 29-32.

[9] Tiwari, R. Biomarkers of silicosis: Potential candidates. Indian J. Occup. Environ. Med., 2005, 9(3), 103.

[10] Pizzimenti, S.; Ciamporcero, E.; Daga, M.; Pettazzoni, P.; Arcaro, A.; Cetrangolo, G.; Minelli, R.; Dianzani, C.; Lepore, A.; Gentile, F.; Barrera, G. Interaction of aldehydes derived from lipid peroxidation and membrane proteins. Front. Physiol., 2013, 4, 242.

[http://dx.doi.org/10.3389/fphys.2013.00242] [PMID: 24027536]

[11] Draper, H.H.; Hadley, M. Malondialdehyde determination as index of 
lipid peroxidation. Methods Enzymol., 1990, 186, 421-431. [http://dx.doi.org/10.1016/0076-6879(90)86135-I] [PMID: 2233309]

[12] Janero, D.R. Malondialdehyde and thiobarbituric acid-reactivity as diagnostic indices of lipid peroxidation and peroxidative tissue injury. Free Radic. Biol. Med., 1990, 9(6), 515-540.

[http://dx.doi.org/10.1016/0891-5849(90)90131-2] [PMID: 2079232]

[13] Fogelman, A.M.; Shechter, I.; Seager, J.; Hokom, M.; Child, J.S.; Edwards, P.A. Malondialdehyde alteration of low density lipoproteins leads to cholesteryl ester accumulation in human monocytemacrophages. Proc. Natl. Acad. Sci. USA, 1980, 77(4), 2214-2218. [http://dx.doi.org/10.1073/pnas.77.4.2214] [PMID: 6769124]

[14] Krötz, F.; Sohn, H-Y.; Pohl, U. Reactive oxygen species: players in the platelet game. Arterioscler. Thromb. Vasc. Biol., 2004, 24(11), 1988-1996.

[http://dx.doi.org/10.1161/01.ATV.0000145574.90840.7d] [PMID: 1 5374851]

[15] Griveau, J.F.; Dumont, E.; Renard, P.; Callegari, J.P.; Le Lannou, D. Reactive oxygen species, lipid peroxidation and enzymatic defence systems in human spermatozoa. J. Reprod. Fertil., 1995, 103(1), $17-26$.

[http://dx.doi.org/10.1530/jrf.0.1030017] [PMID: 7707295]

[16] Yu, B.P. Cellular defenses against damage from reactive oxygen species. Physiol. Rev., 1994, 74(1), 139-162.

[http://dx.doi.org/10.1152/physrev.1994.74.1.139] [PMID: 8295932]

[17] Iwasaki, A.; Gagnon, C. Formation of reactive oxygen species in spermatozoa of infertile patients. Fertil. Steril., 1992, 57(2), 409-416. [http://dx.doi.org/10.1016/S0015-0282(16)54855-9] [PMID: 1735495]

[18] Abdoljalil, M. Plasma Malondialdehyde Level and Erythrocyte Antioxidant Enzyme Activity in Patients with Type II Diabetes Mellitus in Gorgan. J. Ardabil Uni. Med. Sci., 2006, 6(2), 183-187.

[19] Khosrowbeygi, A.; Zarghami, N.; Nouroozzadeh, J.; Ghaffari, M. Relationship between level of lipid peroxidation markers in seminal plasma and sperm motility. J. Reprod. Infertil., 2004, 5(2), 129-139.

[20] Rostami, M.; Jarfi, M. The Evaluation of serum nitrite, nitrate and malonyldialdehyde levels in smokers. Med Lab J., 2009, 3(2), 46-52.

[21] Mirzaei, R.; Allameh, A.; Mortazavi, B.; Khavanin, A.; Kamalian, N. Effects of loud noise on oxidation and lipid peroxidation variations of liver tissue of rabbit. Zahedan J. Res. Med. Sci., 2009, 11(2), 11-17.

[22] Sakhvidi, M.J.Z.; Biabani Ardekani, J.; Firoozichahak, A.; Zavarreza, J.; Hajaghazade, M.; Mostaghaci, M.; Mehrparvar, A.; Barkhordari, A. Exhaled breath malondialdehyde, spirometric results and dust exposure assessment in ceramics production workers. Int. J. Occup. Med. Environ. Health, 2015, 28(1), 81-89.

[http://dx.doi.org/10.13075/ijomeh.1896.00262] [PMID: 26159950]

[23] Liu, H-H.; Lin, M-H.; Liu, P-C.; Chan, C-I.; Chen, H-L. Health risk assessment by measuring plasma Malondialdehyde (MDA), urinary 8hydroxydeoxyguanosine (8-OH-dG) and DNA strand breakage following metal exposure in foundry workers. J. Hazard. Mater., 2009, 170(2-3), 699-704.

[http://dx.doi.org/10.1016/j.jhazmat.2009.05.010] [PMID: 19497668]

[24] Kotur-Stevuljevic, J.; Memon, L.; Stefanovic, A.; Spasic, S.; Spasojevic-Kalimanovska, V.; Bogavac-Stanojevic, N.; Kalimanovska-Ostric, D.; Jelić-Ivanovic, Z.; Zunic, G. Correlation of oxidative stress parameters and inflammatory markers in coronary artery disease patients. Clin. Biochem., 2007, 40(3-4), 181-187. [http://dx.doi.org/10.1016/j.clinbiochem.2006.09.007] [PMID: 17070 511]

[25] Nardi, J.; Nascimento, S.; Göethel, G.; Gauer, B.; Sauer, E.; Fão, N.; Cestonaro, L.; Peruzzi, C.; Souza, J.; Garcia, S.C. Inflammatory and oxidative stress parameters as potential early biomarkers for silicosis. Clin. Chim. Acta, 2018, 484, 305-313.

[http://dx.doi.org/10.1016/j.cca.2018.05.045] [PMID: 29860036]

[26] Azari, M.R.; Rokni, M.; Salehpour, S.; Mehrabi, Y.; Jafari, M.J.; Moaddeli, A.N. Risk assessment of workers exposed to crystalline silica aerosols in the east zone of Tehran. Tanaffos, 2009, 8(3), 43-50.

\section{(C) 2019 Gholami et al.}

This is an open access article distributed under the terms of the Creative Commons Attribution 4.0 International Public License (CC-BY 4.0), a copy of which is available at: (https://creativecommons.org/licenses/by/4.0/legalcode). This license permits unrestricted use, distribution, and reproduction in any medium, provided the original author and source are credited. 